\title{
Study on Tourists' Waste Classification Behavior: An extension of the Theory of Planned Behavior model
}

\author{
Zhoujie Wang ${ }^{1, *}$, and Xuewang Dong, ${ }^{1, *}$ \\ ${ }^{1}$ School of Tourism \& Urban-Rural Planning, Zhejiang Gongshang University, 310018 Hangzhou, China
}

\begin{abstract}
Garbage problem is becoming more and more prominent. The most effective solution to the waste problem is waste minimization, and waste classification is the prerequisite and basis for waste minimization. At present, the effectiveness of waste classification in tourist destinations is not satisfactory. It is crucial to improve the level of tourists' participation in destinations. In this study, we investigated tourists in Shanghai from the perspective of the factors that influence tourists' waste classification. A total of 249 questionnaires were distributed through the questionnaire method. 236 questionnaires were valid questionnaires. We tested the hypotheses using structural equation modeling. The results of the study showed that waste classification attitude has a significant positive effect on intention, subjective norm has a significant positive effect on attitude toward waste classification, moral norm has a significant positive effect on attitude, and perceived behavioral control is not significantly related to intention. Finally, depending to the analysis of the influence of different factors on tourists' participation in waste classification in Shanghai. We suggest strategies to increase the level of Shanghai tourists' waste classification. This is of great theoretical and practical significance in order to accelerate the development of waste separation in Shanghai and improve the urban ecological environment.
\end{abstract}

\section{Introduction}

With the development of economy and the improvement of the national living standard, the garbage problem is becoming more and more serious. Human activities generate waste that must be managed. The garbage problem is an issue that plagues the whole world[1]. As the largest developing country, China has the largest population and the second largest economy in the world. According to the National Environmental Statistics Bulletin, the total amount of urban household waste in China is increasing year by year. By the end of 2018, the national household waste has reached 22.802 million tons. However, the recycling rate of garbage is not optimistic. Waste classification is one of the most effective methods of waste management. It is also an important aspect of testing and promoting the progress of social civilization. According to the Statistical Bulletin on Cultural and Tourism Development, there were 11924 A-level scenic spots in China by the end of 2018, with a total of 6,024 million visitors for the year. Scenic areas undoubtedly play an important part in the process of promoting waste classification. For a long time, waste management has been a big headache for destinations. After the peak of tourism, many destinations are all over the garbage, plastic bags, empty bottles and so on. As prominent public place, classification in destinations can not only protect the natural environment of destinations, but also reduce the cost of waste management. Strengthen the main responsibility of destinations to do a good job of waste classification, not only rely on scenic spots, but also the policy guidance. Tourists' behavior is closely related to the environmental problems of tourist destinations.

Therefore, what factors can be studied that will affect tourists' waste classification? How do these factors affect the tourists' behavior? How to guide tourists to actively practice waste classification? These issues are very important to destinations. This study is based on the theory of planned behavior and the normative activation model to examine the drivers and influence mechanism of tourists' waste classification behavior.

\subsection{Literature review and conceptual framework}

\subsubsection{TPB and moral norm}

The theory of planned behavior (TPB) is a theory of social psychology that focuses on researching human behavior[2]. It has been applied to predict a wide variety of tourists' behaviors. It is a rational decision making model using three key independent variables to predict behavioral intentions[3]. The main influencing factor, intention directly affects the implementation of the behavior. The more positive an individual's attitude towards environmental behavior and the greater the perceived normative pressure, the greater the sense of control over the implementation of environmental behavior, the more difficult it is to implement the

\footnotetext{
* Corresponding author: cnwangz@,163.com; dxuewang@163.com
} 
behavior. The less likely an individual is to engage in an environmentally responsible behavior, the more likely they are to do so. Attitudes are the degree to which an individual approves of performing an action. Subjective norm are the perceptions that an individual has of the people around him or her when he or she performs an action of pressure. Perceived behavioral control is an individual's perception of the difficulty of performing a behavior on his or her own, subject to internal skills, abilities, external opportunities, resources, and other influences. The Norm Activation Model (NAM) is a theory developed by Schwartz to explain the pro-social behavior of individuals. It is rooted in altruistic behaviors[4]. While pro-social behavior is directly driven by moral norm. Moral norm is activated by two key factors, sense of consequence, and responsibility attribution. A moral code is the sense of moral obligation an individual has towards a particular action before performing or avoiding that action. Recently, a metaanalysis of the psycho-social determinants of proenvironmental behavior found empirical support for the utility of including moral norms in a TPB like framework[5]. Moral norm as either a predictor of intention, attitude, or a substitute for attitude in the study of general conservation behavior which included items about recycling. Kaiser concluded that moral norm may already be represented in people's attitudes towards conservation behavior, or perhaps that moral norms are a powerful antecedent of conservation attitudes[6].

\subsubsection{Conceptual framework}

The model included four constructs from the theory of planned behavior (attitude, subjective norm, perceived behavioral control, and intention) and one construct from the norm activation model (moral norm).

The attitude is a reflection of tourists' perceptions of waste classification. The higher the perception and more positive the evaluation of the tourists, the more inclined they are to classify. Subjective norm mainly refers to the perception of the tourists when performing the act of waste classification from the social pressure exerted by people and groups that influences their decision making when implementing waste classification. The greater the pressure tourists perceived, the stronger their attitudes towards waste classification. Moral norm is the perceived personal moral and social responsibilities of individuals when they perform a particular act. As a special cultural principle, ethics is a code of conduct that people are required to follow as a matter of course in their daily lives, which has a significant impact on the individual's daily behavior patterns have a latent guiding and restraining effect. The stronger the influence of tourists' moral codes on their waste classification, the stronger their attitude. Perceived behavioral control refers to the factors that promote or hinder classification behavior, including intrinsic factors such as visitors' willpower and ability, and external factors such as time and space of classification facilities. Tourists' waste classification behavior is constrained by certain objective conditions, and the stronger tourists' perception of waste classification, the more they can overcome the problems related behavior. The greater the ability to overcome barriers, the greater the intention to engage in waste classification in destinations. Hypotheses were derived from the conceptual model. In this study, the following questions were asked:What is the influence of attitude on tourists' classification intention? What is the influence of subjective norm on tourists' classification attitude? What is the influence of moral norm on tourists' classification attitude? What is the influence of perceived behavioral control on tourists' classification intention?

\subsection{Questionnaire design and data collection}

In this study, the questionnaire used was compiled according to the theory of planned behavior theoretical framework, the norm activation model theoretical framework and some waste classification literature. The first part of this questionnaire included 15 items to measure the model's 5 independent variables: behavioral intention (BI), attitude towards the behavior (ATT), subjective norm (SN), moral norm $(\mathrm{MN})$, perceived behavioral control (PBC). Measures were from Wan[7], Ajzen [8], Chan [9], Heidri [10], Lopezmosquera [11].

A five-point Likert Scale was used to measure the components of the proposed model (i.e., $1=$ strongly disagree to $5=$ strongly agree). This questionnaire also included questions about respondent's demographic information (such as age, gender, education level, monthly income and profession).

Shanghai is one of the most famous and developed cities in China. As early as 2000, China started to carry out pilot programs for waste separation and recycling in eight cities including Shanghai[12]. Shanghai's resident population of 24 million in 2018 will be about 9 million tons of waste per year, with a personal daily waste output of about $1.1 \mathrm{~kg}$. In 2018, President Xi Jinping stressed that waste sorting is a new fashion. On July 1 , 2019, Shanghai officially implemented the Municipal Waste Management Regulations. The regulation sits on the most stringent waste classification measure in history. Shanghai is a first-test city to promote the classification of municipal household waste, and it is also one of the most famous tourism destinations in China. Shanghai's visitor numbers continue to grow significantly, with annual visitor arrivals increasing from 26,748.08 million in 2013 to 348.7058 million in 2018. In 2018, Shanghai's annual tourism revenue exceeded 500 billion yuan, and tourism has become one of the pillar industries in Shanghai. Shanghai is representative in the area of waste classification, and it is urgent to improve the level of tourist waste classification, so this study selected Shanghai tourists as a sample, find the influence factors of tourists' garbage classification behavior, in order to provide some suggestions for the management of tourists' waste classification in Shanghai, and provide reference for other cities.

Sixty copies of the questionnaire were distributed in a pilot test to ensure that the questions could be clearly understood. This then became the final version. We surveyed tourists in Shanghai. 249 questionnaires were 
distributed at study area. And 249 questionnaires were completed, 13 were eliminated because they were completed carelessly. This resulted in 236 valid questionnaires. The recovery rate was $100 \%$, and the effective rate was $94.8 \%$. Out of 236 responses, $32.2 \%$ of the participants were male and $67.8 \%$ were female. Approximately $30.9 \%$ of the participants were married and $69.1 \%$ were unmarried. The age group of $18-30$ $(75.4 \%)$ is the largest group. The education level group of Bachelor's Degree is the largest group. Demographic information is presented in Table 1 .

Table 1. Demographic Characteristics $(\mathrm{N}=236)$.

\begin{tabular}{|c|c|c|c|}
\hline Variable & Classification & $\mathrm{N}$ & $\%$ \\
\hline \multirow{2}{*}{ Gender } & Male & 76 & 32.2 \\
\hline & Female & 160 & 67.8 \\
\hline \multirow{2}{*}{$\begin{array}{l}\text { Marriage } \\
\text { status }\end{array}$} & Married & 73 & 30.9 \\
\hline & Unmarried & 163 & 69.1 \\
\hline \multirow{5}{*}{$\begin{array}{l}\text { Education } \\
\text { level }\end{array}$} & Primary & 4 & 1.7 \\
\hline & $\begin{array}{c}\text { Lower } \\
\text { Secondary }\end{array}$ & 19 & 8.1 \\
\hline & $\begin{array}{c}\text { Upper } \\
\text { Secondary }\end{array}$ & 27 & 11.4 \\
\hline & $\begin{array}{l}\text { Bachelor's } \\
\text { Degree }\end{array}$ & 164 & 69.5 \\
\hline & $\begin{array}{c}\text { Master's or } \\
\text { above }\end{array}$ & 22 & 9.3 \\
\hline \multirow{5}{*}{ Age } & Under 18 & 7 & 3.1 \\
\hline & $18-30$ & 178 & 75.4 \\
\hline & $31-45$ & 39 & 16.5 \\
\hline & $46-60$ & 10 & 4.2 \\
\hline & 60 or above & 2 & 0.8 \\
\hline \multirow{5}{*}{$\begin{array}{l}\text { Monthly } \\
\text { Income } \\
\text { (RMB) }\end{array}$} & 3000 or less & 129 & 54.6 \\
\hline & $3001-5000$ & 43 & 18.2 \\
\hline & $5001-8000$ & 38 & 16.1 \\
\hline & $8001-10000$ & 15 & 6.4 \\
\hline & $\begin{array}{l}10001 \text { or } \\
\text { more }\end{array}$ & 11 & 4.7 \\
\hline
\end{tabular}

\section{Results}

\subsection{Statistics for the construct items}

Table 2. presents the scores statistics for the constructs items used in this study. All variables presented results reaching the extremes of the proposed scale. We tested a five-factor model using CFA to examine the validity of the measurement model. All standardized factor loading of the measurement model was between 0.681 to 0.894 . The composite reliability values were checked in order to check internal consistency. The values were between 0.823 to 0.884 , exceeding the minimum suggested value of 0.70 .
Table 2. Descriptive Statistics $(\mathrm{N}=236)$.

\begin{tabular}{|c|c|c|c|c|}
\hline Variable & Maximum & Minimum & Mean & $\begin{array}{c}\text { Std. } \\
\text { Deviation }\end{array}$ \\
\hline QUE01 & 5 & 1 & 3.75 & 1.02 \\
\hline QUE02 & 5 & 1 & 3.87 & 1.01 \\
\hline QUE03 & 5 & 1 & 4.13 & 0.84 \\
\hline QUE04 & 5 & 1 & 4.45 & 0.74 \\
\hline QUE05 & 5 & 1 & 4.51 & 0.70 \\
\hline QUE06 & 5 & 1 & 4.50 & 0.75 \\
\hline QUE07 & 5 & 1 & 4.24 & 0.84 \\
\hline QUE08 & 5 & 1 & 4.20 & 0.86 \\
\hline QUE09 & 5 & 1 & 4.24 & 0.86 \\
\hline QUE10 & 5 & 1 & 4.48 & 0.69 \\
\hline QUE11 & 5 & 1 & 4.50 & 0.71 \\
\hline QUE12 & 5 & 1 & 4.51 & 0.71 \\
\hline QUE13 & 5 & 1 & 4.17 & 0.89 \\
\hline QUE14 & 5 & 1 & 4.17 & 0.92 \\
\hline QUE15 & 5 & 1 & 4.24 & 0.89 \\
\hline
\end{tabular}

\subsection{Structural model}

The structural model was tested using a structural equation modeling with maximum-likelihood estimation by the software AMOS 23.0. In relation to tourists' waste classification, the hypothesized model shows a good fit to the data, $\mathrm{CMIN} / \mathrm{DF}=1.399, \mathrm{RMR}=0.037$, RMSEA $=0.041, \mathrm{GFI}=0.938, \mathrm{TLI}=0.979$, NFI $=0.946$.

The standardized path coefficients of ATT to BI is $0.316, \mathrm{t}=3.246>2.58, \mathrm{p}<0.001$. The standardized path coefficients of $\mathrm{MN}$ to ATT is $0.859, \mathrm{t}=9.624>2.58, \mathrm{p}<$ 0.001 . The standardized path coefficients of SN to ATT is $0.145, \mathrm{t}=2.822>2.58, \mathrm{p}<0.05$. However, the result suggests that PBC does not directly affect $\mathrm{BI}$ ( $\beta=0.142$, $\mathrm{t}=1.579<1.96, \mathrm{p}>0.05)$.

\section{Discussion and Conclusions}

Many studies relating to waste classification have focused on residents. A detailed study on waste classification of tourists is lacking. The aim of this study was to develop a comprehensive model of tourists' waste classification intention. The model proposed two determinants of intention and two antecedents of attitude.

\subsection{Policy implications}

Establishing sound laws and regulations on waste classification. In order to effectively manage tourists' waste classification behavior, the construction and improvement of relevant laws and regulations must be strengthened. At present, the central government and local governments have issued and revised laws, regulations and management rules on waste, but the restrictions on tourists is still vague. We need to learn from the best practices of developed countries to raise the illegal cost of tourists' garbage not sorted. We need 
to take the perspective of tourists, the perspective of tourist destinations, the perspective of classification, the standard and the way of classification in tourist destinations. The specifics make detailed provisions to clarify the responsibilities that tourists need to assume for violating the waste classification, providing tourists with effective legal basis and guarantees.

Strengthen the publicity of waste classification. Most of current waste classification awareness efforts are directed at the community, and there is still little awareness of the tourism industry. The large amount of waste generated and the wide range of management involved is a major environmental challenge in tourist destinations. It is difficult to rely on the government alone to truly solve the waste problem at its source. Only the active participation of the majority of tourists in waste classification can be the solution to the problem. Environmental conferences can be held in the destinations and tourists can be invited to listen to their reasonable suggestions; environmental protection experts and scholars can be organized. Conducting destination awareness campaigns and distributing brochures on waste classification; promoting it through multiple channels, using the online channels such as Facebook, QQ, mobile phone text messages, and offline channels such as bulletin boards, newspapers, magazines, and volunteers. Using persuasive written content, infectious propaganda videos, to carry out a variety of activities such as prize contests and photo contests on waste classification, and organization of public service activities for tourists to participate in waste classification. Through publicity, tourists will be made aware that waste classification is being promoted by the government and that it has a bearing on the improvement of the living environment in tourist destinations.

Strengthen the education of tourists on waste classification. Destinations are still weak in educating tourists. It's important to educate tourists to develop a better understanding of waste classification. Tour guides can give specific instructions to tourists to account for classification. Educational slogans for classification can be designed and displayed at tourist attractions. The government can popularize classification to the tourists by distributing scientific and educational brochures with scientific design.

Strengthen the infrastructure for waste classification in destination areas. Convenient garbage facilities in tourist destinations are essential for tourists. The supply of garbage facilities should be enhanced and the geographical layout of the facilities should be properly planned according to the tourists' travel routes. The bins should be clearly marked with the categories of waste classification and brief descriptions of the details, so that tourists can fully understand the destination information about waste.

\subsection{Limitations and future research}

The study has some limitations. Only Shanghai was chosen for the research, which has an impact on the generalizability of the findings. In the future, more destinations can be selected for in-depth research to verify the generalizability of the results. On the research model, there are many factors that influence tourists' waste classification behavior, and this paper only selects attitudes, subjective norm, moral norm and perceived behavioral control, and other factors can be added to the model in the future for further study.

\subsection{Conclusions}

A large number of tourists entering, put a lot of pressure on the ecology of the site. Tourism is high consumption activity. Tourists generate a lot of garbage during their journey. Waste classification in destinations is important. How to guide tourists to sort their garbage is an urgent issue for destinations. This study was conducted from the perspective of the influential factors that affect the waste classification of tourists in Shanghai. Data were collected through questionnaire survey method and the hypothesis was tested using structural equation model. The results of the study showed that attitude toward waste classification has a significant positive effect on intention, subjective norm of waste classification has a significant positive effect on attitude, moral norm of waste classification has a significant positive effect on attitude, perceived behavioral control is not significantly related to intention. This study makes recommendations including improving the laws and regulations on waste classification, strengthening education and publicity of waste classification, and strengthening the construction of waste separation facilities.

\section{References}

1. F. Aziz, H. Arof, N. Mokhtar, M. Mubin, M. S. A. Talip, Measurement. 65, 19-28.(2015).

2. C. J. Armitage, M. Conner, Brit J Soc Psychol. 40, 471-499.(2001).

3. E. Goh, B. W. Ritchie, J. Wang, Tourism Manage. 59, 123-127.(2017).

4. S. H. Schwartz, J. A. Howard, Soc Psychol Quart. 43, 441.(1980).

5. S. Bamberg, G. Moser, J Environ Psychol. 27, 1425.(2007).

6. F. G. Kaiser, Pers Indiv Differ. 41, 71-81.(2006).

7. C. Wan, G. Q. Shen, A. Yu, Environ Sci Policy. 54, 409-418.(2015).

8. I. Ajzen, Organ Behav Hum Dec. 50, 179211.(1991).

9. L. Chan and B. Bishop, J Environ Psychol. 36, 96102.(2013).

10. A. Heidari, M. Kolahi, N. Behravesh, M. Ghorbanyon, F. Ehsanmansh, N. Hashemolhosini, F. Zanganeh, J Mater Cycles Waste. 20, 20412053.(2018).

11. N. Lopezmosquera, T. Garcia, and R. Barrena, J Environ Manage. 135, 91-99.(2014).

12. X. Meng, Z. Wen, and Y. Qian, Resour Conserv Recy. 128, 535-545.(2018). 